\title{
Las transformaciones de la actividad agrícola en Uruguay: "el entorno institucional" $y$ sus consecuentes implicancias sobre el funcionamiento del mercado. Una mirada desde la nueva economía institucional
}

The Transformations of Agricultural Activity in Uruguay, the Institutional Environment and its Consequent Implications for the Functioning of the Market. From the Perspective of Neoinstitutionalism

\author{
Myriam Felperín \\ Centro de Estudios Agrarios y Agroindustriales (CIEA) - \\ Facultad de Ciencias Económicas - Universidad de Buenos Aires - Argentina \\ http://orcid.org/0000-0002-0082-0506 \\ myriamfelperin@fibertel.com.ar \\ Mercedes Muro de Nadal \\ Centro de Estudios Agrarios y Agroindustriales (CIEA) - \\ Facultad de Ciencias Económicas - Universidad de Buenos Aires - Argentina \\ http://orcid.org/0000-0003-3953-2912 \\ murodenadal@gmail.com
}

Fecha de recepción: 13 de marzo de 2015 Fecha de aceptación: 4 de septiembre de 2015

Sugerencia de citación: Felperín, M. y Muro de Nadal, M. (2015). Las transformaciones de la actividad agrícola en Uruguay: "el entorno institucional" y sus consecuentes implicancias sobre el funcionamiento del mercado. Una mirada desde la nueva economía institucional.

tiempo\&economía, 2(2), 33-47 


\section{Resumen}

Los procesos de globalización e internacionalización de la economía han operado profundos cambios en los mercados en general y en el sector agroindustrial en particular; han impuesto nuevas normas de producción y comercialización que incluyen en su cadena de valor a una multiplicidad de sujetos (productores, proveedores, distribuidores) que intervienen y se interrelacionan a lo largo del proceso.

En este sentido, ha quedado superada la visión fragmentada y horizontal de la producción agraria que la concebía como una actividad sencilla que nacía y finalizaba en el establecimiento rural, instaurando una clara división entre la agricultura, el almacenamiento, la industria y la comercialización.

El objetivo de este trabajo es analizar, desde una perspectiva teórica, el rol de las instituciones en el marco de las transformaciones de la actividad agrícola de Uruguay, sus consecuentes implicancias sobre el funcionamiento del mercado y los costos de transacción que emergen de ello.

Palabras clave: agroindustria, agricultura, recursos naturales y energía, desarrollo económico, planificación y políticas de desarrollo, cambio tecnológico e investigación y desarrollo.

Códigos JEL: Q00, Q1, Q2, Q3, Q4, 01, 02, 03

\section{Abstract}

The processes of globalization and internationalization of the economy have operated profound changes in the markets in general and in the agribusiness sector in particular; have imposed new rules on production and marketing that include in their value chain to a multiplicity of subjects (producers, suppliers, distributors) involved and interact throughout the process.

In this sense has been overcome fragmented and horizontal viewing of agricultural production conceived as a simple activity that was born and ended in the rural setting, with a clear division between agriculture, storage, and marketing industry.

The aim of this work, is to analyze from a theoretical perspective, the role of institutions under the transformations of the agricultural activity of Uruguay, consequent implications for the functioning of the market and transaction costs emerging from it.

Keywords: agribusiness, agriculture, natural resources and y energy, economic development, planning and development policies, technological change, research and development.

JEL Codes: Q00, Q1, Q2, Q3, Q4, 01, 02, 03 


\section{Introducción}

Los procesos de globalización e internacionalización de la economía han operado profundos cambios en los mercados en general y en el sector agroindustrial en particular; han impuesto nuevas normas de producción y comercialización que incluyen en su cadena de valor a una multiplicidad de sujetos (productores, proveedores, distribuidores) que intervienen y se interrelacionan a lo largo del proceso. Consecuentemente, y a partir del cambio del paradigma tecno-productivo, ${ }^{1}$ será necesaria la incorporación de renovados criterios analíticos que nos permitan interpretar y conceptualizar al mercado y a las organizaciones.

En este sentido, ha quedado superada la visión fragmentada y horizontal de la producción agraria que la concebía como una actividad sencilla que nacía y finalizaba en el establecimiento rural, estableciendo una clara división entre la agricultura, el almacenamiento, la industria y la comercialización. En cada una de esas etapas, los actores se relacionaban con la siguiente en "función de un esquema de precios (actuales o futuros), donde oferentes y demandantes pujaban entre sí sobre la base de productos mínimamente estandarizados. Actualmente y cada vez más, es posible verificar la existencia de relaciones contractuales previas que establecen pautas y especificidades particulares sobre productos a recibir".2

Por su parte, la producción y el comercio de granos y oleaginosas en Uruguay han experimentado en los últimos años una sustancial transformación que se relaciona estrechamente con el pronunciado incremento de la demanda internacional de alimentos, tanto de insumos como de productos finales, y con el cambio de paradigma que el sector viene gestando desde inicios de los años dos mil. Ambos procesos han modificado necesariamente en múltiples sentidos el comportamiento de los agentes. La mayor competitividad y el éxito de cada eslabón local (grandes o pequeños productores, proveedores de insumos, etcétera) dependen no sólo de conductas individuales, sino también de acciones auspiciadas por el Estado. En este sentido, un marco institucional adecuado facilitaría, sin duda, la gestión, y con ello, la disminución de costos en las transacciones.

El objetivo de este trabajo es analizar, desde una perspectiva teórica, el rol de las instituciones en el marco de las transformaciones de la actividad agrícola de Uruguay, sus consecuentes implicancias sobre el funcionamiento del mercado y los costos de transacción que emergen de ello.

\section{Algunas precisiones conceptuales Instituciones y costos de transacción}

El incremento de los costos de transacción ha sido una característica histórica en los países del Tercer Mundo, y hoy, los intentos de atraer inversiones y la necesidad de ser competitivo en la arena internacional resultan incompatibles con la existencia de instituciones que funcionan deficientemente. Dichas instituciones determinan, en efecto, el entorno en el que operan los

1 Utilización de semillas modificadas genéticamente con sus herbicidas asociados, nuevas técnicas de cultivo, siembra directa, organización de la empresa agropecuaria, etcétera.

2 Ver Anlló, Bisang y Salvatierra, G. (2010, p.11); véase especialmente, para integración vertical en agronegocios, el trabajo de Victoria (2011). 
mercados. Un entorno institucional débil permite mayor arbitrariedad por parte de las agencias estatales y los funcionarios públicos. Por el contrario, las instituciones que resultan eficientes incluyen acuerdos para compartir información y controlar su cumplimiento, de acuerdo con patrones establecidos por el régimen, y se adaptan a los cambios de capacidades de sus miembros.

Las instituciones, según North, son las reglas de juego en una sociedad, o bien son las limitaciones ideadas por el hombre que dan forma a la interacción humana. En consecuencia, el cambio institucional es el modo en que las sociedades evolucionan en el tiempo, y constituye una clave fundamental para comprender el cambio histórico (North, 1993, p. 13).

En esta línea de pensamiento, las instituciones revisten el comportamiento de "constricciones" que moldean la interacción individual y organizativa, tendiendo de este modo a reducir la incertidumbre, en la medida en que proporcionan una estructura de vida diaria, estableciendo de manera formal o informal acciones o comportamientos determinados. Dichas instituciones difieren según los países y según los sectores de la economía a los cuales nos estamos refiriendo, dado que el desarrollo institucional de los mercados no es el mismo para todos ellos. Como mencionamos con anterioridad, las limitaciones pueden ser formales (por ejemplo, las normas) o informales (cuando nos referimos a acuerdos o códigos de conducta). Estas limitaciones siempre afectan el funcionamiento y desempeño de los distintos mercados; ya sea desde un punto de vista territorial o del bien o servicio que se intercambia, éstos siempre son influidos por las instituciones que regulan y determinan su comportamiento.

Las primeras se expresan a través de constituciones, leyes, acuerdos, decretos y resoluciones, y conforman las reglas bajo las cuales funcionan los sectores. No obstante, cada uno de ellos tiene códigos de conducta y comportamientos propios de su dinámica y su impronta cultural.

La norma tiene adicionado un castigo cuando no se cumple con el compromiso, y el mismo requiere ser identificado y luego sancionado, lo cual no resulta ser una tarea de bajo costo ni sencilla. Las violaciones de los códigos de conducta, en cambio, están vinculadas a la presencia, o no, de incentivos que promuevan o desalienten determinadas acciones. En algunos casos, los dos actores se ponen de acuerdo para violar los contratos; en consecuencia, lo escrito pasa a ser una formalidad, y el funcionamiento real es la sistemática violación de los acuerdos alcanzados.

Al igual que las instituciones, los organismos constituyen también mecanismos de interacción. Si observamos los costos del marco institucional, vemos que son el resultado de éste y de los organismos creados para asegurar el funcionamiento. Lo que debemos distinguir son las reglas y los jugadores.

[...] Las instituciones constituyen las normas subyacentes del juego, mientras que el peso específico en las organizaciones recae en su papel como agentes del cambio institucional; por consiguiente, el énfasis está marcado por la interacción entre instituciones y organismos. Los organismos se crean con un propósito deliberado como consecuencia de la oportunidad, la que en general obedece al conjunto de limitaciones existentes $y$, el curso de sus empeños por lograr sus objetivos, constituye la fuente principal del cambio institucional. Separar el análisis de las normas subyacentes de la estrategia de los jugadores, es un prerrequisito necesario para crear una teoría de las instituciones. (North, 1993, pp. 15-16). 
En el análisis acerca de la diferencia entre instituciones y organismos, North ha buscado respuestas para aquellos casos que examinan y explican por qué persisten instituciones ineficientes a pesar de que "deberían existir presiones competitivas" que condujeran a su eliminación. Precisamente, en la interacción entre ambas estará la respuesta que señala la direccionalidad del cambio institucional.

Las instituciones, junto con las limitaciones ordinarias de la teoría económica, determinan las oportunidades existentes y los instrumentos creados para aprovechar esas oportunidades. A medida que esos organismos se modifican, se alteran también las instituciones. La vía resultante del cambio institucional está conformada por:

1- el entrecruzamiento que es producto de la relación simbiótica entre las instituciones y las organizaciones que se han creado por evolución como consecuencia de la estructura incentivadora que proporcionan esas instituciones; y 2- por el proceso de retroalimentación por medio del cual los humanos percibimos y reaccionamos a los cambios que se dan en el conjunto de oportunidades. (North, 1993, p. 19)

Entonces, la posibilidad de captar oportunidades estará íntimamente ligada a un conjunto de incentivos que en buena medida se compadece, de acuerdo con lo que nos dice la historia económica, con el marco institucional subyacente. Al respecto, es posible señalar que en América Latina, y a partir de las últimas décadas, se ha puesto especial énfasis en el rol de las instituciones, el capital social y la cultura cívica como determinantes del marco de incentivos y constricciones para el desarrollo público y privado.

Sin embargo, a pesar de ello y de los sustanciales esfuerzos emprendidos por casi todos los países de la región para reformar y modernizar el Estado, persisten ciertos rasgos estructurales del pasado, haciendo que el contexto en el que se intentan captar esas oportunidades tienda a incentivar actividades que promueven más la actividad redistributiva que la productiva, creen más monopolios que condiciones de competencia y se ocupen de restringir oportunidades, en lugar de aumentarlas. Pocas veces incentivan inversiones en educación que tiendan a aumentar la competitividad. En definitiva, esos organismos sólo serán eficientes en hacer a la sociedad más improductiva. Esta vía persistirá porque los costos de negociación de los mercados políticos y económicos, junto con los modelos subjetivos de sus integrantes, no los dirigen hacia resultados proporcionalmente más eficientes (North, 1993, p. 21).

El dilema del prisionero nos plantea que todos podrían mejorar su situación si cooperaran. Sin embargo, en un escenario en donde los individuos y las naciones - como un agregado de decisiones colectivas - basan sus decisiones en la desconfianza mutua, los costos suelen ser más elevados. Esta alternativa tiene un costo que no pueden permitirse los países de los márgenes, empujados a competir en un mundo globalizado donde los países centrales imponen las condiciones de juego.

\section{Costos de transacción}

En las últimas décadas, los economistas teóricos han estado cada vez más concentrados analizando la eficiencia de las instituciones. La emergencia del nuevo institucionalismo dentro de 
la teoría económica contribuyó en gran medida a este tema. Desde este marco teórico, el análisis de los costos de transacción cumple un rol en la explicación de la eficiencia institucional. Aunque en la empresa neoclásica los costos organizacionales no existen, es posible analizar que resulta sustancial el contraste entre la empresa neoclásica hipotética y las condiciones reales de algunos procesos de organización.

Existen dos explicaciones alternativas para los costos de transacción, cada una de ellas vinculada a teorías diferentes. Por un lado, la principal interpretación de la teoría de costos de transacción la planteó Williamson en 1975 (Williamson 1989 y 1991), y luego apareció un enfoque alternativo de los costos de transacción a partir de la teoría evolucionista de Langlois, en 1984. En tanto que la primera implica un análisis estático de los costos de transacción, en el segundo este análisis es dinámico.

El enfoque del nuevo institucionalismo identifica los costos de transacción como una de las variables claves que define la estructura y el diseño institucional. De todas maneras, este marco teórico no es homogéneo, dado que hay interpretaciones alternativas de los costos de transacción con diferentes grados de desarrollo.

En términos generales, en cualquier diseño institucional, el análisis de los costos organizacionales es vital, dado que tienen un rol crítico en la determinación de la eficiencia del sistema bajo estudio. En esta línea es posible mencionar a Arrow (1969, pp. 133-135), ya que identifica los costos de transacción con los costos de "hacer funcionar el sistema". De este modo, los mismos están asociados con un nivel general de la eficiencia del sistema económico.

De todos modos, es posible considerar a Coase (1937) como uno de los precursores de la distinción entre costos de transacción y de producción. Desde su análisis, los costos relativos de transacción determinan el diseño institucional entre las empresas y el mercado. Ambos, las empresas y el mercado, son considerados como instituciones alternativas con diferentes mecanismos para coordinar las transacciones económicas. En tanto que el mecanismo de precios es el instrumento coordinador del mercado, y la firma tiene también una función coordinadora. Coordina los recursos a través de los mecanismos organizacionales.

Así, la diferencia entre el mercado y las empresas está en la naturaleza de los contratos. Los contratos de las empresas tienen un carácter más abierto y continuado. Cada contrato requiere varios grados de cuidadosa y permanente coordinación administrativa entre las partes. En esta línea, es posible argumentar que la esencia de la empresa es la naturaleza de la coordinación involucrada.

Como lo señala North, todo intercambio tiene un costo de transacción que consiste en los recursos necesarios para medir los atributos físicos y legales que se intercambian, más un descuento de incertidumbre, que refleja los grados de imperfección en la mediación, vigilancia y garantía de intercambio. Cuanto mayor resulte el potencial de un tercero para influir en el valor de los atributos que se incluyen en la función de utilidad del "comprador" (es decir, cuanto mayor sea el poder arbitrario público o privado), mayor será la tasa de descuento. En otras palabras, a mayor incertidumbre del comprador, menor será el valor del bien comprado. Del mismo modo, la estructura institucional determinará los riesgos que significará para el "vendedor" que el contrato se cumpla o no, o que el "vendedor" sea indemnizado en caso de no concretarse la operación. De ahí la importancia de la seguridad jurídica en la historia económica. El grado de incertidumbre respecto a la seguridad de los derechos constituye una distinción crítica entre 
los mercados relativamente eficientes de los países más desarrollados y aquellos en proceso de desarrollo (North, 1993, cap. VIII, pp. 86-88).

A diferencia del modelo neoclásico, en donde la información es perfecta, no existiendo costos de transacción, el valor del bien que se transfiere da por sentado, no sólo una información perfecta, sino también una seguridad también perfecta sobre derechos de propiedad. Aquí, tanto el comprador como el vendedor han podido determinar, sin costo, el valor de todos los atributos, y como no hay incertidumbre o inseguridad, los modelos de oferta y demanda definirán el valor del bien. De acuerdo con este análisis, estaríamos básicamente en presencia de una función de producción sin costos de organización, supervisión, coordinación y monitoreo.

Para el mercado real de producción de bienes y servicios, la complejidad es mucho mayor. El marco institucional afectará costos de transformación y transacción; estos últimos, debido a la conexión directa entre las instituciones y los costos de transacción, y los primeros, por influir en la tecnología empleada. Se requieren recursos para definir y proteger derechos de propiedad y para hacer cumplir los convenios. Las instituciones, junto con la tecnología empleada, determinan esos costos de negociación. Se necesitan recursos para transformar los factores de producción de tierra, trabajo y capital y conseguir producción de bienes y servicios, y esa transformación es una función no sólo de la tecnología empleada, sino de las instituciones. Por consiguiente, las instituciones desempeñan un papel clave en los costos de producción.

Cuando el costeo de la medición y aseguración significa formas complejas y relevantes de intercambio, esto se logra a través de las instituciones. Desde este marco teórico, las instituciones consisten en restricciones informales, reglas formales y sus características de consolidación. De acuerdo con North, la efectividad de la consolidación de los acuerdos es el determinante individual más crucial del desempeño económico de las instituciones alternativas. En esta línea de pensamiento, la "eficiencia" institucional, en definitiva, puede explicarse por la capacidad de consolidar o fortalecer sus acuerdos. Siguiendo este enfoque, el crecimiento económico exitoso es la historia de la evolución de instituciones más complejas que hacen posible que relaciones de intercambio cooperativas puedan extenderse por largos periodos.

Con el fin de entender aquellas condiciones que afectan el fortalecimiento de los acuerdos, es necesario considerar en forma explícita dos presunciones o supuestos conductuales asociados a esta línea de pensamiento: racionalidad limitada y oportunismo. Ambos supuestos son necesarios para explicar situaciones "hold up", entendiendo que este "hold up" se produce si cualquier agente económico (vendedor o comprador) explota una oportunidad para extraer renta económica renegociando los términos o buscando redefinir los términos durante la renegociación del contrato.

De este modo, es posible argumentar que las condiciones de asimetría de información entre los actores incrementan las posibilidades de costos de transacción. A partir de este argumento, dado que las instituciones son las que proveen las reglas del juego de las relaciones humanas, podrían asimismo pensarse como reglas de diferentes niveles de las interacciones humanas. De este modo, Williamson define el problema de la organización económica como un problema de la contratación. Resulta muy interesante la distinción que realiza de los costos de transacción en dos tipos: ex ante y ex post. Los primeros son los de bosquejar, negociar y asegurar un acuerdo. 
El último tipo de costos de transacción incluye las siguientes situaciones: 1) El problema de la mala adaptación, cuando las transacciones tienden a desalinearse; 2) Los costos de haggling, o dispersión, en los que se cae si se hacen esfuerzos bilaterales para corregir los desalineaciones ex post; 3 ) los costos de poner en marcha y mantener funcionando, asociados a las estructuras de gobierno (a menudo, no de la Justicia) a las cuales se refieren las disputas originadas previamente; 4) Los costos asociados a la necesidad de asegurar determinados compromisos y armar compromisos seguros. Los costos ex ante y ex post de los contratos son interdependientes y deberían abordarse en forma simultánea antes que secuencial. Desde este enfoque, la evaluación de los costos de transacción puede efectuarse en un análisis institucional comparativo. Además, también destaca Williamson que es importante saber si las relaciones organizacionales (como las prácticas contractuales, estructuras de gobierno) alineadas con los atributos de las transacciones pueden ser previstas o no por el cálculo de los costos de transacción (Williamson, 1989, p. 22).

Es obvio, entonces, que el costo de negociación exhibe de qué modo funcionan las instituciones formales e informales tanto en la economía como en la escala mayor de una sociedad. Esta estructura conforma, finalmente, el costo de transacción en el nivel individual, y, cuando los economistas se refieren a mercados eficientes, suponen la existencia implícita de una red de limitaciones.

Finalmente, al evaluar los costos de realizar transacciones en los mercados de los países en desarrollo, North ha observado que los costos son mayores a partir de una estructura formal muy poco consolidada, al igual que el nivel de cumplimiento obligatorio. De modo tal que los costos se elevan, debido a que la falta o ausencia de salvaguardias formales de los derechos de propiedad restringe la actividad a sistemas de intercambio especializados que proporcionan tipos autorreforzadores de contratos. El resultado será que, si los derechos de propiedad son inseguros, si hay barreras de entrada y restricciones monopólicas, las empresas que tienden a maximizar utilidades tenderán a buscar horizontes breves y a arriesgar poco capital fijo. Grandes empresas con capital fijo importante podrán existir únicamente bajo la protección del gobierno mediante subsidios, tarifas de protección y sobornos al sistema político, mezcla que difícilmente dará como fruto una eficiencia productiva (North, 1989, pp. 92-93).

\section{El avance agrícola en Uruguay}

Tras décadas de una reducida producción agrícola en Uruguay, a partir de la zafra 2001/2002, este país ingresó en una fase expansiva. Los factores que coadyuvaron a la retracción del sector desde mediados de los años cincuenta del siglo XX hasta principios de los años dos mil se relacionaron estrechamente con su especialización pecuaria, la caída mundial de los precios agropecuarios desde 1998 hasta comienzos de los años dos mil; la fuerte devaluación brasileña a comienzos de 1999 — que derivó en una pérdida de competitividad de la moneda uruguaya - y la crisis económico-financiera de Argentina en 2002, que provocó gran cantidad de retiros de fondos bancarios de residentes argentinos, contagiando al sistema bancario uruguayo (Sáez, 2009).

El gran avance de la producción de soja en Uruguay se inició entre 2002/2003, si bien los primeros registros de producción de esa oleaginosa datan de la década de 1970. A partir de 2003, 
el crecimiento fue muy rápido, y se convirtió en el principal cultivo del país, pasando de 12.000 ha sembradas de soja en 2000-2001, a una extensión cercana a 1.000.000 ha en el período 20102011. (DIEA, Series Históricas, 2011, en REDES, p. 3)

El incremento exponencial llegó entonces de la mano del paquete tecnológico soja transgénica-siembra directa-glifosato. El valor bruto de producción (VBP) agropecuario creció un 150\% (en US\$) entre 2000 y 2009, pasando la soja a representar el 39,6\% VBP de la agricultura extensiva de secano, mientras que el VBP de los granos experimentó un aumento de aproximadamente un $800 \%$ (DIEA, 2011). En este nuevo escenario surgieron nuevos actores que impactaron decididamente en la morfología agraria. Siguiendo la caracterización de Arbeletche y Carvallo, los "nuevos agricultores", la mayoría de procedencia argentina, de2000 a 2009, "pasaron de no existir a representar el 15\% de los productores y el $57 \%$ de la superficie cultivada." Ello ha influido especialmente sobre la performance de los agricultores tradicionales, que redujeron su participación tanto en número como en superficie pasaron de no existir a representar el 15\% de los productores y el $57 \%$ de la superficie cultivada., y de modo mucho más determinante sobre los pequeños productores, muchos de los cuales debieron abandonar la producción (los productores familiares, que representaban el 15\% del área, pasaron al 6\% en 2009) (Santos et al., 2011, pp. 5 ss.; DIEA, 2011).

La crisis argentina de 2002 agravó la situación económica de productores agropecuarios uruguayos chicos y medianos, que, jaqueados por las deudas, vieron una salida en la venta o el alquiler de sus tierras a argentinos que llegaron a sembrar soja. A ellos, el precio de la tierra les resultó muy conveniente, y además contaban con la ventaja impositiva de no pagar retenciones a las exportaciones, que sí pagaban en la Argentina.

Sólo con soja, según estimaciones de la Dirección de Estadística Agropecuaria (DIEA), en la zafra 2007-2008 se sembraron en Uruguay unas 450.000 hectáreas, cincuenta veces más que en la campaña 1999-2000. En ese impactante crecimiento, la participación argentina influyó mucho, hasta el punto que un 54\% del área de soja ha sido explotada por productores que ingresaron al país a partir de 2002, la mayoría de la orilla vecina.

Una tendencia similar — aunque más tenue- ocurre con el trigo, el maíz y el arroz. Pero, más allá de las inversiones, hay otros aportes argentinos al crecimiento agropecuario uruguayo. La alianza aportó además mucha información y conocimientos técnicos en lo comercial, organización del trabajo en redes, software para llevar la gestión de producción y análisis de riesgos. A partir de 2006 - animadas por el éxito de los primeros inversores, la suba de los precios internacionales, y apostando al aumento en la escala - arriban empresas transnacionales y regionales "que hoy controlan buena parte de la fase primaria y de acopio, consolidando un complejo altamente concentrado en todas sus fases" (Santos et al., 2011, p. 2).

La principal característica de este sector fue la compra de campos grandes y, básicamente, el arriendo de campos de pequeños productores. Estos grupos inversores, por el volumen que implicaron y la competencia que se desató, hicieron subir mucho el precio de las tierras hasta 2013. Las modalidades societarias que se adoptaron variaron desde el armado de compañías uruguayas o mixtas, siendo éstas las que más se utilizaron. 
A medida que esta estrategia se fue difundiendo y asentando — la suba de los precios de los commodities - llegaron también inversiones argentinas extra sector. En este caso, se trató de hombres de negocios con excedentes para invertir que buscaban asegurar su capital y percibir una alta renta libre de retenciones.

La alta demanda de tierras para comprar y arrendar llevó a una casi desaparición de campos en todo Uruguay que se ofrecieran en arrendamiento o venta y al achicamiento de la brecha de precios de los arrendamientos agrícolas entre Uruguay y Argentina, que llegaron en 2012 a un 20 o $25 \%$ menos en Uruguay, cuando tradicionalmente eran un 50\% menores. Existe una generalizada aceptación de las causas que explican el fenómeno de la llegada masiva de argentinos en busca de buenos campos agrícolas para cultivar soja.

Por la infraestructura necesaria, los campos costeros sobre el río Uruguay fueron los más buscados, pero también los departamentos de Durazno, Florida y Flores, que eran zonas ganaderas y lecheras, mantuvieron una alta demanda de campos de la mano de los capitales argentinos. A partir de 2009, el movimiento avanzó hacia los departamentos de Colonia, San José, Soriano y Río Negro, que eran campos vírgenes de cultivos agrarios (Merlo y Muro de Nadal, 2014).

En esta etapa, los nuevos agricultores trabajaron aumentando la escala productiva mediante arrendamientos, con escaso capital fijo y canalizando fondos de inversión o fideicomisos y subcontratando las operaciones técnicas de servicios de maquinarias e insumos. Desarrollaron en general secuencias de agricultura con alta presencia de soja, mediante planes de producción establecidos previamente y reduciendo riesgos al distanciar geográficamente las siembras.

Los analistas Arbeletche y Carballo distinguen, además de los pools de siembra ${ }^{3}$ y megaempresas agropecuarias, otros dos subtipos de nuevos agricultores: a) los agricultores muy grandes con ganadería como complemento, que cuentan con capital fijo y utilizan tierras de su propiedad que trabajan grandes extensiones complementando la agricultura con la ganadería, sembrando áreas con secuencias de agricultura y combinándolas con ganadería en zonas marginales; y b) los medianeros de agricultura continua, que llegaron cuando ya se había iniciado el "boom agrícola" y accedieron a la tierra a través de arrendamientos y medianerías y desarrollaron soja continua (Arbeletche y Carballo, 2006).

Desde el punto de vista de los productores uruguayos, resulta de interés ver el tratamiento que Santos hace del tema, en relación con la dinámica resultante de los diez últimos años en el agro uruguayo, y con cómo la irrupción de una agricultura de tipo empresarial ha condicionado los distintos actores. Santos resalta que si bien no se han registrado conflictos entre los "viejos" y "nuevos" productores, sí se han destacado tendencias netamente diferenciadas:

a) Los productores que se han podido acoplar a las nuevas realidades del sector, en especial los "viejos agricultores", empresarios agrícolas, ganaderos medios y grandes que han permanecido en la actividad, habiendo en muchos casos incursionado en la ganadería.

3 Un pool de siembra es una asociación de inversores que tiene como finalidad la obtención de un rendimiento económico mediante una explotación agraria. En un pool de siembra participan inversores de diferente tamaño de capital, englobando de este modo agentes financieros ajenos al sector agropecuario tradicional. Los actores intervinientes en un pool de siembra pueden ser varios, entre los que podemos mencionar inversores, administradores, propietarios de un pool de siembra, dado que los propietarios de campos o contratistas pueden formar parte o no de un pool de siembra. Véanse, Santos et al. $(2012$, p. 4) y Oyhantcabal y Narbondo (2011). 
b) Aquellos productores que abandonan la agricultura extensiva o rubros tales como lechería o apicultura, desplazándose desde "el rubro o territorio que ocupaba hacia otras actividades productivas"; en algunos casos, la reinserción ocurre dentro de la estructura agropecuaria, y en otros, tal desplazamiento conlleva una reducción de escala, "en especial productores familiares de rubros que compiten por tierras con la agricultura". Es importante, tal como lo expresa el autor, que el desplazamiento de actividad no supone un grado de proletarización de los involucrados, teniendo en cuenta que si bien no pueden competir "con los grandes capitalistas, si pueden apropiarse de la renta del suelo y/o convertirse en empresarios de servicios agrícolas y de esta forma podrían convertirse en socios de los pools de siembra".

c) Quienes han dejado la actividad, separados de los medios de producción y subsistencia se reinsertan en el sistema como asalariados (el sector más reducido en este esquema de transformación) (Santos, 2012, pp. 6 y 7).

\section{Algunas consideraciones}

Afortunadamente, se extiende por toda América Latina, positiva y ampliamente, una demanda y conciencia mayores de un déficit institucional en la región. Ciertamente, ni el diagnóstico ni los tratamientos resultan todavía suficientemente claros, convincentes y compartidos. Pero siempre es así cuando estamos ante verdaderos cambios de paradigma. $Y$ el cambio más prometedor que en la actualidad está viviendo América Latina es mental y cultural, expresado en la emergencia, no exenta de conflictos, de nuevos paradigmas tanto en lo económico como en lo político, lo social o lo empresarial (Prats Catalá, 1996, pp. 447 y ss.). Como sostiene Steven Levitsky (2015), a pesar de los problemas (la amenaza de crisis de gobernabilidad es mucho más alta con tasas más bajas de crecimiento, y es más difícil gobernar con el $1 \%$ de crecimiento que con un $8 \%$. Hace cinco o seis años veíamos a presidentes con el $60 \%$ o $70 \%$ de aprobación. Ahora muy pocos superan el 20\%), las democracias sobreviven, pero aún persisten Estados e instituciones frágiles, y un sistema político fragmentado. La buena noticia es que hay "mucha, muchísima sociedad civil, cada vez más vibrante" (Schamis, p. 2).

Teniendo en cuenta la importancia insoslayable que imprimen los datos contextuales para el presente análisis, resulta preciso señalar que tanto la economía de los costos de transacción como los demás enfoques contractuales se han efectuado ignorando los aspectos explícitamente políticos, y han considerado el diseño institucional como dado.

Sin embargo, la política no puede ser una "caja negra" que pueda ser ignorada en el intento de llegar a una comprensión cabal de los mecanismos de incentivos y los problemas de diseño organizativo; por el contrario, el mercado político ejerce una influencia determinante en el diseño institucional y organizativo. No sólo necesitamos considerar qué estructuras organizativas minimizan los costos de producción y transacción conjuntamente para obtener mayores niveles de eficiencia relativa y una estructura de incentivos adecuada, sino preguntarnos qué diseño institucional es relativamente más eficiente. La diferencia entre el enfoque de los costos de transacción y la aproximación representada por Douglas North es, por tanto, la importancia que este último concede en su esquema teórico al ámbito político y, particularmente, al diseño y cambio institucionales. 
En esta línea, podríamos sostener que los cambios operados en la dinámica del mercado de tierras y, con ello, en la composición de la estructura agraria de Uruguay responden a una multiplicidad de factores concomitantes, encontrando gran parte de su explicación en el comportamiento de las cadenas agroindustriales nacionales (teniendo en cuenta el contexto en donde se mueve ese mercado), así como en los procesos asociados a interacciones económicas regionales e internacionales, en condiciones agroecológicas satisfactorias y expectativas de ganancias a futuro en tierras de menor costo, en una visión empresarial más dinámica y competitiva, y en el marco de una política económica previsible y estabilidad jurídica e institucional.

Este último aspecto nos resulta particularmente importante para contextualizar el "buen clima de negocios" experimentado y advertir que el entorno institucional de Uruguay ha suministrado los incentivos necesarios para asegurar, como nos sugiere la nueva economía institucional -y en ella, la teoría de los costos de transacción-, que dadas las asunciones de racionalidad limitada y comportamiento oportunista, los contratos no pueden prever todas las contingencias ex ante, por lo que los contratos son necesariamente incompletos, y en este sentido, adquiere especial relevancia el funcionamiento de las estructuras de gobierno y autoridad para asegurar que no se vulneren las garantías en su cumplimiento. En este sentido y estando de acuerdo con ello, hemos podido advertir una profusión de trabajos centrados en la importante función de aquellas instituciones que protegen los derechos de propiedad y garantizan el cumplimiento de los contratos: podríamos llamarlas creadoras de mercado. Autores tales como D. Rodrik, F. Trebbi, A. Subramanian señalan que para "mantener el ímpetu del desarrollo, lograr flexibilidad ante las conmociones" y facilitar una distribución socialmente aceptable de la carga frente a dichas conmociones "habrá que tratar de construir -además-, otros tipos de instituciones que clasifican en reguladoras, estabilizadoras y legitimadoras de mercado.

Mientras las primeras se ocupan de"las externalidades, las economías de escala y la información imperfecta (ejemplo de ello son las entidades reguladoras de las telecomunicaciones, transporte y servicios financieros); las estabilizadoras de mercado coadyuvan a asegurar una inflación baja, minimizar la volatilidad macroeconómica y evitar las crisis financieras (pudiendo mencionar en este caso a los bancos centrales, regímenes cambiarios y normas presupuestarias fiscales). Por su parte, las legitimadoras, es decir las que proporcionan seguro de protección social, se ocupan de la redistribución y controlan el conflicto (sistema de pensiones, planes de seguro de desempleo y otros fondos sociales)"(Rodrik, Subramanian, 2003, pp. 31-34). Para lograr, entonces, un escenario de desarrollo y crecimiento económico, serán imprescindibles instituciones que impulsen y garanticen el cumplimiento de los contratos, al mismo tiempo, se vuelven necesarias, la existencia de otro conjunto de reglas que permitan su sustentabilidad en el largo plazo.

Respecto de los actores económicos protagonistas de esta transformación productiva, los productores se incorporaron, en su mayoría, a este proceso de transformación, incluso aquellos que fueron parte de la "dinámica de acoplamiento" — viejos propietarios o los que arrendaron sus campos-, haciéndolo en ausencia de conflicto con los nuevos empresarios extranjeros. Esto se explica por el alto costo de las tierras y de los arrendamientos, que les permitieron a los "viejos agricultores" percibir altos montos y disponer de tiempo libre para dedicarlos a otras actividades productivas o laborales y, en algunos casos, convertirse en socios de los pools de siembra vendiendo servicios. En algunos casos se constituyeron sociedades mixtas entre ambos. Sólo en un porcentaje relativamente bajo, especialmente los medianeros chicos o propietarios endeudados, por desventajas generadas por la falta de capital suficiente y, ante la expansión de 
los arrendamientos, el incremento del precio de sus campos, diferente poder de negociación y asimetría informativa, decidieron vender y abandonaron la actividad, quedando fuera del sistema de producción agraria.

Para que esta radiografía no resulte incompleta, es importante remarcar que esta realidad está íntimamente vinculada al proceso de concentración y tenencia de la tierra que viene produciéndose en Uruguay "en forma relativamente constante desde 1956 hasta la actualidad, y tiene un carácter creciente y acumulativo" (Vassallo, 2006, p. 56; ver también Vassallo, 1994).

Por lo dicho hasta ahora, es posible acordar que se trata de un proceso económico profundo y expansivo que, durante estos últimos diez años, ha cambiado la fisonomía rural del país, y que esas transformaciones se desenvolvieron en el marco de reglas y certidumbre institucionales; sin embargo, existe una serie de interrogantes y cuestionamientos (desde distintos sectores que expresan sus respectivos intereses) acerca de cómo se articularán a futuro el desarrollo y crecimiento del sector agroindustrial con una estrategia de desarrollo más incluyente y sostenible en el largo plazo.

Los principales cuestionamientos están relacionados con la relativa pérdida de soberanía o de control del Estado sobre los recursos naturales y con los potenciales riesgos de un uso no racional sobre los mismos. En esta dirección, el poder ejecutivo ha intentado aplicar el Impuesto a la Concentración de Inmuebles Rurales (ICIR), iniciativa que finalmente fue declarada inconstitucional por la Corte Suprema de Justicia. Entre las voces que más se opusieron aparecen la Federación Rural del Uruguay y la Asociación Rural del Uruguay. También en esa posición, y considerándolo como un "impuesto ideológico", se han manifestado en contra de la reimplantación del Impuesto al Patrimonio — que ya tiene media sanción del Senado—, que se aplicará a unos 1400 productores con extensiones superiores a las 2000 ha. ${ }^{4}$ En el debate que se llevó a cabo ante la Comisión de Hacienda, el Presidente del Congreso Nacional de Intendentes mostró sus discrepancias, claro, no por intereses sectoriales sino porque ahora los intendentes no percibirán los recursos originalmente prometidos ni se conformará el fideicomiso para la reparación de los caminos rurales. Los recursos para las intendencias irán desde 2015 a Rentas Generales y a la UTEC (Universidad Tecnológica del Uruguay),y luego a las comunas. Recordó que en 2004 en el interior se transportaban por caminos nueve millones de toneladas de producción anuales por todo concepto; en 2010 esa cifra subió a unos 15 millones, y dijo que, según las previsiones, en 2020 serán 20 millones anuales de producción transportada. ${ }^{5}$

En lo que respecta a la sostenibilidad de la producción agropecuaria ${ }^{6}$ y al riesgo que implica la aplicación de un modelo tecnológico que pueda resultar depredatorio de los recursos naturales, se ha puesto en marcha un sistema que concilia lo público con lo privado. El Estado corresponsabiliza a los propietarios en la conservación del suelo, obligando al productor a

4 Diario El País: "El ICIR fue derogado por inconstitucional. Senado votó el impuesto al agro. Los sectores involucrados expresaron su malestar por esta modificación de la tributación del sistema agropecuario y alertaron sobre el riesgo de caída de la actividad en todas sus facetas", 8-5-2013.

5 Diario El País: "Intendentes y el sector agropecuario volvieron a oponerse. El nuevo impuesto al campo será ley en dos semanas", 5-6-2013.

6 Se entiende que un proceso es sostenible cuando ha desarrollado la capacidad para producir indefinidamente a un ritmo en el cual no agota los recursos que utiliza y que necesita para funcionar, y no produce más contaminantes de los que puede absorber su entorno. 
presentar un plan de siembra al Ministerio de Ganadería y Agricultura, un plan de uso y manejo del suelo que cumpla con la condición de estimar la erosión y sea tolerable para esa unidad. La presentación de dicho plan, con la firma conjunta del propietario y de un ingeniero agrónomo que se compromete a que haya un uso responsable, sumada a una fiscalización eficiente y sanciones de hasta 400 mil dólares por el incumplimiento de la norma, constituyen el plan uruguayo de conservación del suelo. ${ }^{7}$

Finalmente, es dable suponer, que todos estos temas-problemas continuarán presentes en futuros escenarios a corto y mediano plazo, y que posiblemente el incremento de mayores costos estará asociado a la disminución de ventajas marginales respecto de tierras de menor productividad relativa; al aumento de costos en infraestructura; a una mayor presión tributaria, y a cómo puedan dirimirse los conflictos y pujas de intereses sectoriales en el cambiante contexto nacional e internacional. También, y considerando la trayectoria socio-política de Uruguay, es probable que dichas cuestiones puedan metabolizarse en un marco de considerable certidumbre y previsibilidad institucional.

\section{Referencias}

Anlló, G., Bisang, R. y Salvatierra, G. (2010). Cambios estructurales en las actividades agropecuarias. De lo primero a las cadenas globales de valor, I. Del mercado a la integración vertical pasando por los encadenamientos productivos, los cluster, las redes y las cadenas globales. Santiago de Chile: Cepal.

Arbeletche, P. y Carvallo, C. (2006). Sojización y concentración de la agricultura uruguaya. XXXIV Congreso de la Asociación Argentina de Economía Agrícola, Córdoba.

Arrow, K. (1969). The organization of economic activity: Issues pertinent to the choice of market versus non-market allocation. En Kenneth J. Arrow (ed.), Collected papers of Kenneth J. Arrow, Vol. 2. Oxford: Blackwell.

Coase, R. (1937). The nature of the firm. Economica N. S., vol. 4.

Dirección de Estadística Agropecuaria (DIEA). (2011). Anuario Estadístico 2011, Montevideo: Dirección de Estadísticas Agropecuarias, Ministerio de Agricultura, Ganadería y Pesca.

Dirección de Estadística Agropecuaria (DIEA), Series Históricas, (2011). REDES, Amigos de la Tierra, Uruguay Sustentable, Impacto del cultivo de soja en Uruguay. Cambios en el manejo de la tierra y en el uso de agroquímicos. http://www.redes.org.uy/wp-content/uploads/2012/07/ Impactos-del-cultivo-de-soja-en-Uruguay.pdf

Langlois, R. (1986). The new institutional economics: An int47roductory essay. En R. Langlois (comp.), Economics as a process: Essays in the new institutional economics. NuevaYork: Cambridge University Press.

Langlois, R. (1984). Internal organization in a dynamic context: Some theoretical considerations. En M. Jussawalla y H. Ebenfield (ed.), Communication and information economics: New perspective. Ámsterdam: North-Holland.

7 Véase: El Nuevo Agro: "El plan de Uruguay para preservar los suelos", 1-2-2013. 
Levitsky, S. (2015). La democracia nunca ha estado mejor. El País, 30-8-2015.

Merlo, S. y M. Muro de Nadal, M. (2014). Análisis de costos comparados de la producción agraria en Uruguay y la Argentina; Buenos Aires. Documentos del Centro Interdisciplinario de Estudios Agrarios, Facultad de Ciencias Económicas, № 9.

North, D.C. (1993). Instituciones, cambio institucional y desempeño económico. México: Fondo de Cultura Económica.

Oyhantcabal, G. y Narbondo, I. (2011). Sojización y concentración de la tierra en Uruguay, el artículo es un Radiografía del agronegocio sojero. Ed. Redes.

Prats Catalá, J. (1996). Gobernabilidad democrática en América Latina finisecular. Instituciones, Gobiernos y Liderazgos. Revista Estudios Internacionales de la Universidad de Chile, 116: 447 y sigs.

Rodrik, D. y Subramanian, A. (2003): La primacía de las instituciones. Revista Finanzas \& Desarrollo, 31-34.

Sáez, R. (2009). Desempeño del sector agropecuario y agroindustrial de Uruguay en el período 2000-2008. Montevideo: IICA.

Santos, C., Oyhantcabal, G. y Narbondo, I. (2012). La expansión del agronegocio agrícola en Uruguay: impactos, disputas y discursos. En GT3 Desarrollo, agro y territorio. Montevideo: Universidad de la República.

Schamis, H. (2015). La hora de los ciudadanos. El País, Suplemento Ideas, la Democracia en América, 30-8-2015.

Vasallo, M. (1994). Estructura Agraria y el Mercado de Tierras: posibles impactos del Mercosur. Montevideo: CIESU.

Vasallo, M. (2006). El mercado de tierra en el Uruguay. Revista del Plan Agropecuario, Montevideo.

Victoria, M. A. (2011). Integración vertical para la cadena de valor en los agronegocios. VII Congreso Americano de Derecho Agrario, México DF, Universidad Autónoma de México.

Williamson, O. (1989). Las instituciones económicas del capitalismo. México: Fondo de Cultura Económica.

Wiliamson, O. (1991). Mercados y jerarquías: su análisis y sus implicancias anti trust. México: Fondo de Cultura Económica. 